
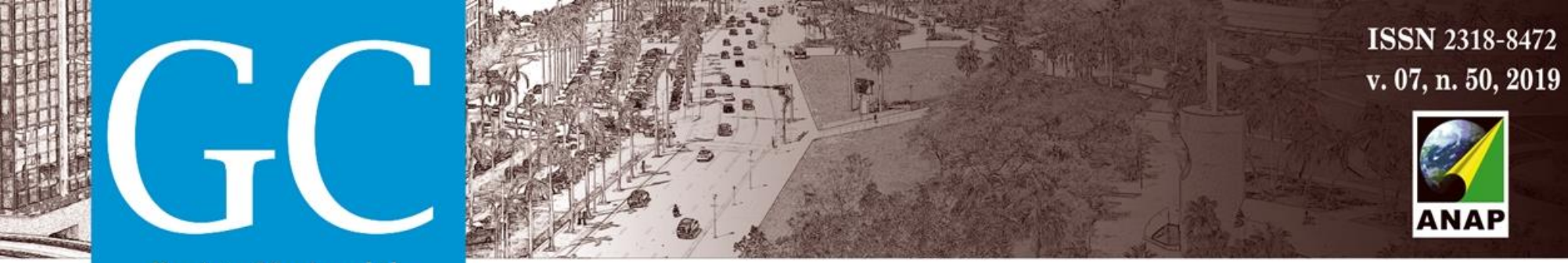

v. 07, n. 50, 2019

Revista Nacional de

Gerenciamento de Cidades

\title{
A imagem simbólica de um território: a marca Barra.
}

The symbolic image of the territory: the Barra brand.

La imagen simbólica de um território: la marca Barra.

Geise Brizotti Pasquotto

Doutora, Universidade de São Paulo, Brasil geisebp@gmail.com 


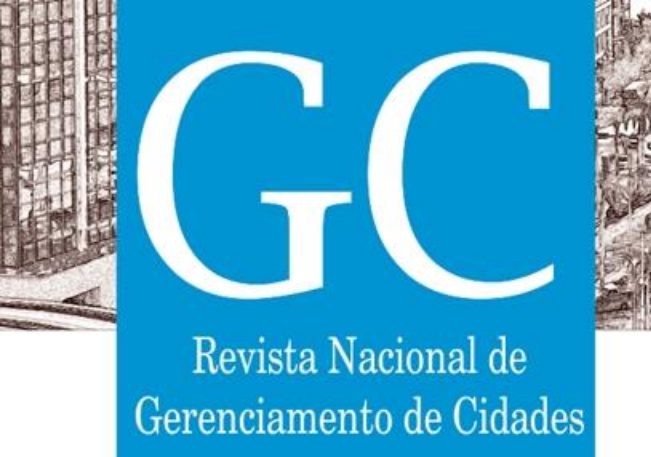

\section{RESUMO}

A Região Administrativa (R.A.) Barra da Tijuca, situada na cidade do Rio de Janeiro, é uma das áreas que obteve um dos maiores crescimentos populacionais, e consequentemente, de domicílios. Este forte crescimento imobiliário também ocasionou um espraiamento para bairros vizinhos, como o de Jacarepaguá. Esse movimento não foi apenas construtivo e sim de uma ressignificação espacial. A marca "Barra" foi inserida juntamente com os novos empreendimentos, fazendo com que estas fronteiras perdessem sua identidade original, tornando-se um local de consumo de um modo de vida. O presente artigo divide-se em dois eixos, o primeiro mostrará dados relativos ao Uso e Ocupação do Solo na R.A. Barra da Tijuca e o segundo abordará o espraiamento do bairro de mesmo nome para além de seus limites.

PALAVRAS-CHAVE: Uso e ocupação do solo. Barra da Tijuca. Marca.

\section{ABSTRACT}

The Barra da Tijuca Administrative Region (A.R.), located in the Rio de Janeiro city, is one of the areas that received one of the highest population growth, and consequently households. This strong real estate growth also caused a spreading to neighboring districts, such as Jacarepagua. This movement was not only constructive, but a spatial reinterpretation, as the brand name " Barra" was inserted along with new developments, making these borders lose their original identity, becoming a place of consumption of a way of life. This article is divided into two axes, the first display data on the Land Use and Occupancy in A.R. Barra da Tijuca and the second will address the sprawling of the same name district beyond its limits.

KEYWORDS: Land use and occupation. Barra da Tijuca. Brand.

\section{RESUMEN}

La Región Administrativa (R.A.) Barra da Tijuca, que se encuentra en la ciudad de Río de Janeiro, es una de las áreas que recibieron un de los más altos crecimientos de la población, y en consecuencia, de las viviendas. Este fuerte crecimiento inmobiliario también causó una difusión a los distritos vecinos, como Jacarepaguá. Este movimiento no sólo era constructive y si de una reinterpretación espacial. La marca "Barra" fue insertado junto con los nuevos desarrollos, por lo que estas fronteras pierden su identidad original, convirtiéndose en un lugar de consumo de una forma de vida. Este artículo se divide en dos ejes, los primeros datos de visualización en el Uso del Suelo y de Ocupación en la AR Barra da Tijuca y el segundo se ocupará de la difusión del mismo distrito nombre más allá de sus límites.

PALABRAS CLAVE: Ocupación y uso del suelo. Barra da Tijuca. Marca. 

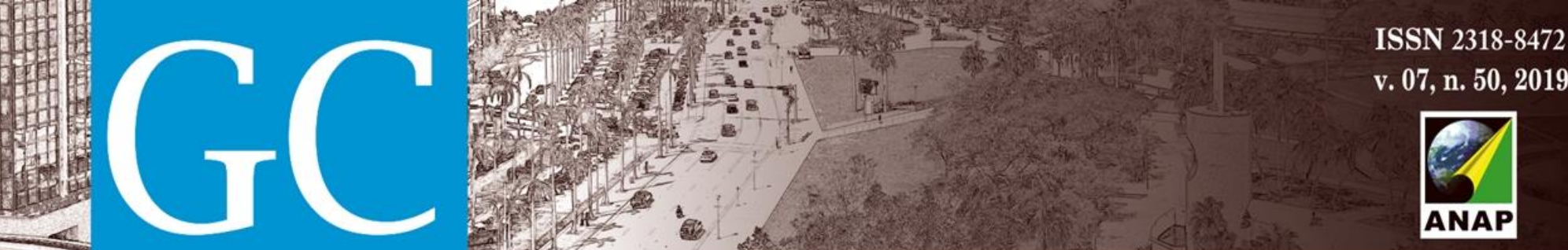

\section{Revista Nacional de}

Gerenciamento de Cidades

da Barra da Tijuca, embora, pelos estudos que serão vistos a seguir, este desenvolvimento não tenha cessado.

Como pode-se notar na imagem abaixo (Figura 1), o eixo Oeste do município demonstrou em dez anos um crescimento populacional intenso. A população no país aumentou $12,3 \%$ nos últimos 10 anos (IBGE, 2000-2010), a cidade do Rio de Janeiro 11,1\% onde 72,54\% foram na R.A. Barra da Tijuca.

Figura 1: Percentual de variação da população entre 2000 e 2010.

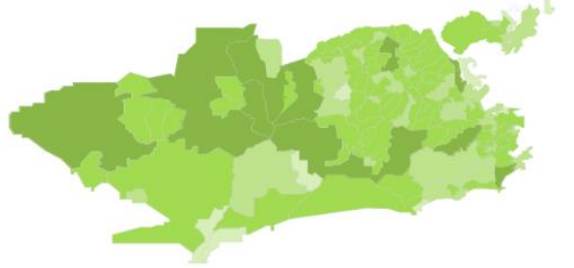

até 5.000

$5.000-20.000$

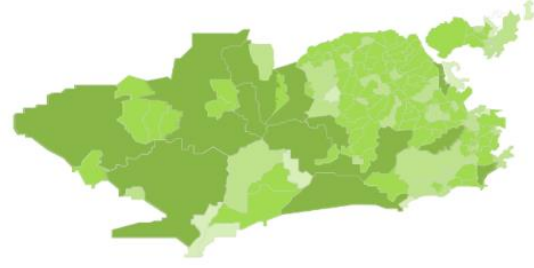

20.000-100.000

Fonte: Os bairros do Rio segundo o Censo 2010. O Globo. Dados: IBGE 2000 e 2010.

Em um percentual de variação da população residente, segundo dados do IBGE de 2000 a 2010, constatou-se que a R.A. Barra da Tijuca cresceu o triplo em relação ao verificado em outras regiões de grande variação populacional, enquanto bairros da Zona Sul perderam moradores. Estes dados mostram um acréscimo populacional intenso, onde a população que era de 174.353 passou a ser de 300.823 (Figura 2).

Figura 2: Percentual de variação da população residente por R.A. entre 2000 e 2010.

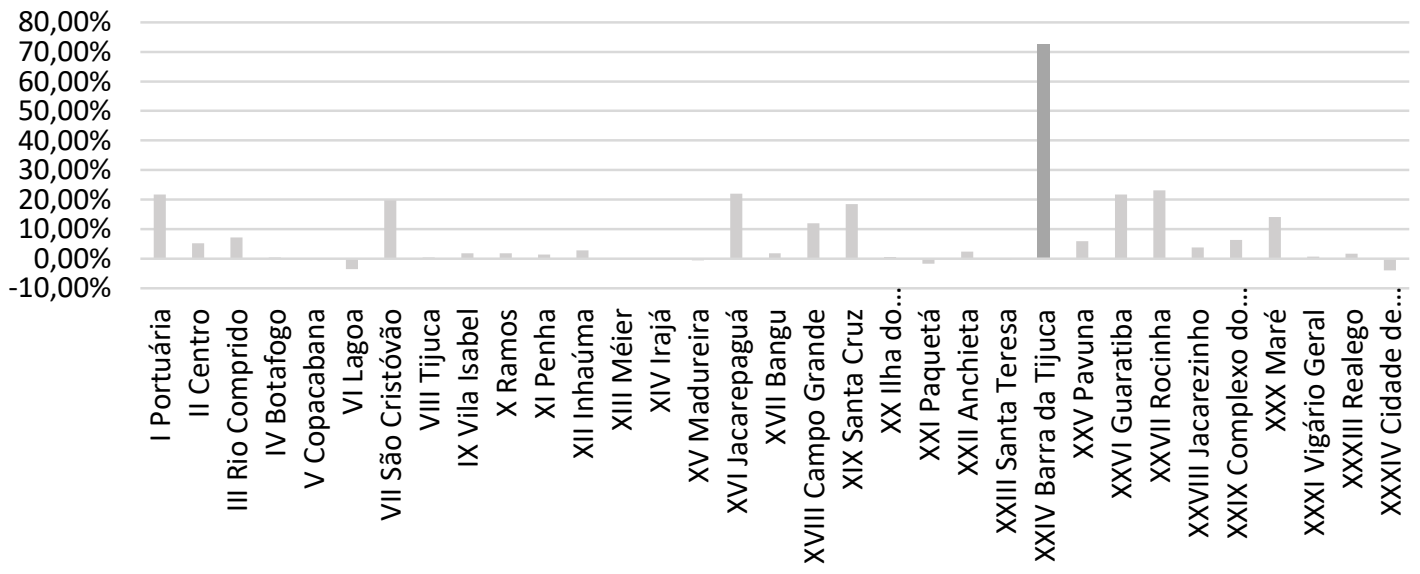

Fonte: Elaborado pela autora com dados do IBGE 2000 e 2010.

Na R.A. Barra da Tijuca, segundo dados do IBGE (2010), destacam-se os bairros de Camorim com crescimento de 150,64\%, Vargem Pequena com 136,22\% e Recreio dos Bandeirantes com 


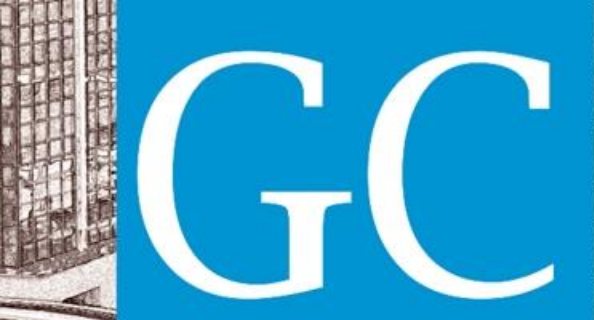

\section{Revista Nacional de}

Gerenciamento de Cidades

Figura 3: Índice de Aproveitamento de Terreno (IAT) Máximo em 2006 e 2011.

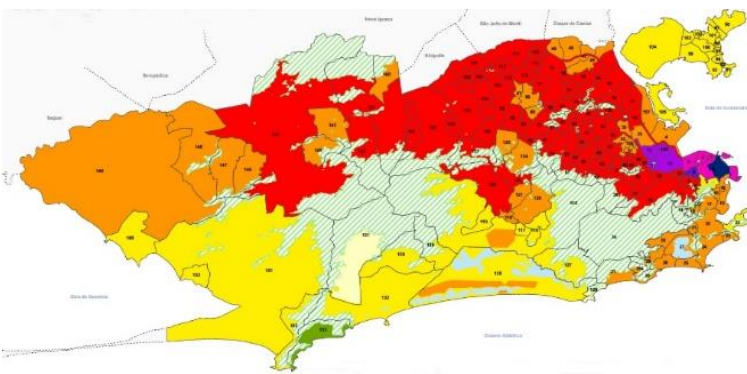

Índice de Aproveitamento de Terreno (IAT) Máximo - Revisão Plano Diretor - Substitutivo $n^{\circ} 3$ (2006)

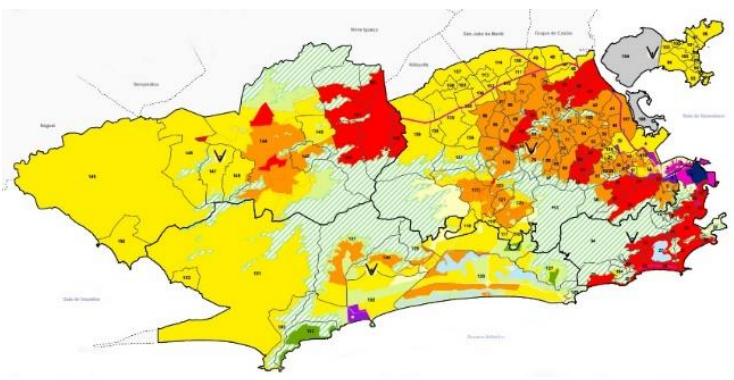

Índice de Aproveitamento de Terreno (IAT) Máximo - Plano Diretor - Lei Complementar n 111/2011
Nota: - Hotéis situados em área abrangida pelo decreto 3.046, de 27 de abril de 1981 (Barra da Tijuca e Jacarepaguá), tem Índice de Aproveitamento de Terreno (IAT) definido por legislação específica.

- Divisão político-administrativa referente a última atualização vigente desde 23 de Novembro de 2004.

- Foi representado neste mapa o IAT máximo para cada bairro, zona, subzona e via de circulação, independente de área.

- Para todas as Áreas de Preservação Ambiental (APAs) e Áreas de Proteção do Ambiente Cultural (APAC) prevalecem os índices estabelecidos nas legislações específicas.

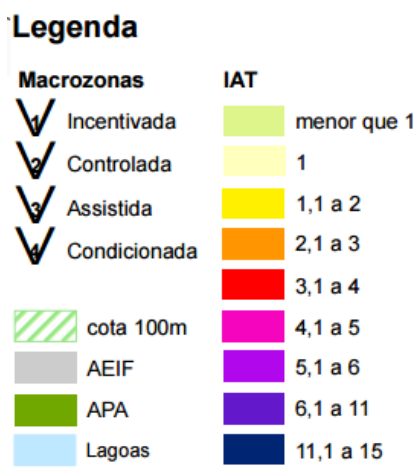

Fonte: Coordenadoria Geral de Planejamento Urbano - CGPU, 2006/2011.

A população residente na R.A. Barra da Tijuca em sua maioria situa-se em domicílios particulares permanentes, sendo que em 2000 existiam 30.612 e em 2010 passou para 65.233 (IBGE, 2000 e 2010), com uma parcela diminuta de particulares improvisados e coletivos. Dentre os domicílios particulares permanentes é nítida a hegemonia da tipologia de apartamentos, totalizando 25.755 contra 4.673 de casas e 184 cômodos (IBGE, 2000), estes $84 \%$ de tipologias verticais refletem no skyline do bairro.

Em 2000 a Barra da Tijuca situava-se em 40 lugar no ranking de número de apartamentos, com 25.755, perdendo apenas para Copacabana, Tijuca e Botafogo respectivamente. Em 2011 ela superou Botafogo, com 49614, situando-se em 3 o lugar, como demonstra a Figura 4. No entanto, é interessante notar o grande aumento no número de apartamentos em onze anos, desproporcional à taxa de crescimento dos outros bairros, demonstrando um grande avanço imobiliário na região. 


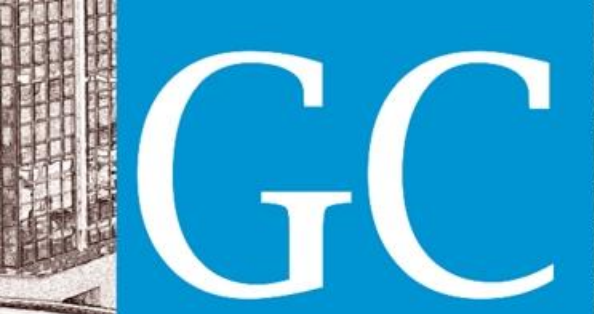

Revista Nacional de

Gerenciamento de Cidades v. 07 , n. 50, 2019

Figura 4: Ranking dos cinco melhores colocados em relação ao número de apartamentos.

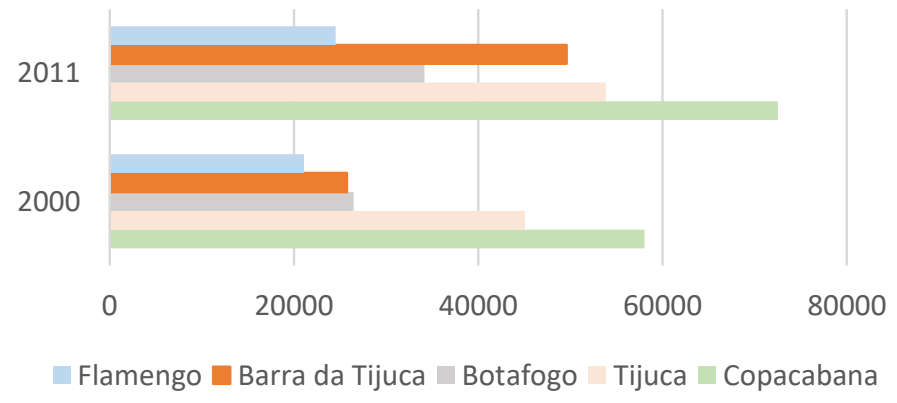

Fonte: Elaborado pela autora com dados do IBGE 2000 e 2011.

Outra análise necessária é de ocupação dos domicílios, verificando se existe uma demanda maior de construção do que de população residente. A concentração de domicílios vagos na Zona Oeste, que já era maior em relação a cidade em 2000, aumentou ainda mais em 2010 (Figura). Em Camorim 45,1\% dos domicílios não tinham moradores no período do censo, em Pedra de Guaratiba, uma em cada cinco moradias estavam vazias, Vargem Pequena possuía $16 \%$ de domicílios sem moradores. Segundo o coordenador de População e Indicadores Sociais do IBGE, Luiz Antônio de Oliveira, a explicação para os números altos de domicílios desocupados é devido aos muitos apartamentos fechados que a especulação imobiliária mantém (OLIVEIRA apud O GLOBO, 2011). Na R.A. Barra da Tijuca em 2000 existiam 18,06\% de domicílios vagos, este número diminuiu em 2010, com 10,64\% (IBGE, 2000-2010). As maiores quantidades de domicílios particulares não ocupados estão na porção oeste da região administrativa (Figura 5)

Figura 5: Percentual de domicílios vagos sobre o total em 2000 e 2010 na cidade do Rio de Janeiro.
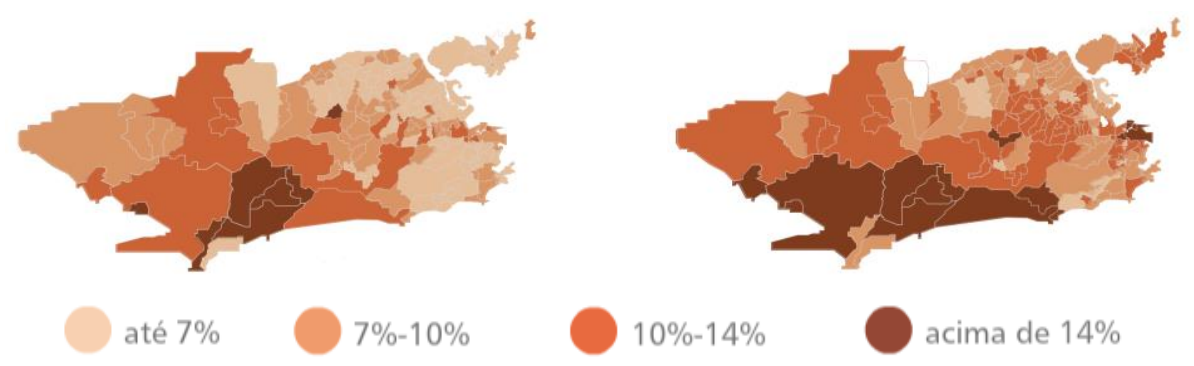

Fonte: Os bairros do Rio segundo o Censo 2010. O Globo. Dados: IBGE 2000 e 2010.

O grupo etário dos responsáveis por domicílio preponderante é adulto, de 40 a 49 anos (IBGE, 2000), embora o grupo de idade maior residente seja de 30 a 34 anos, seguido pelos de 35 a 39 e de 25 a 29. A renda nominal média do responsável pelos domicílios particulares permanentes 


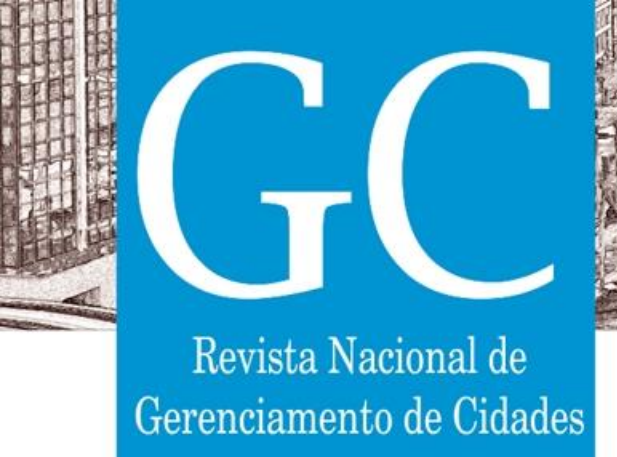

ISSN 2318-8472

Figura 9: Uso do Solo na Cidade do Rio de Janeiro e na Barra da Tijuca em 2004 e 2012
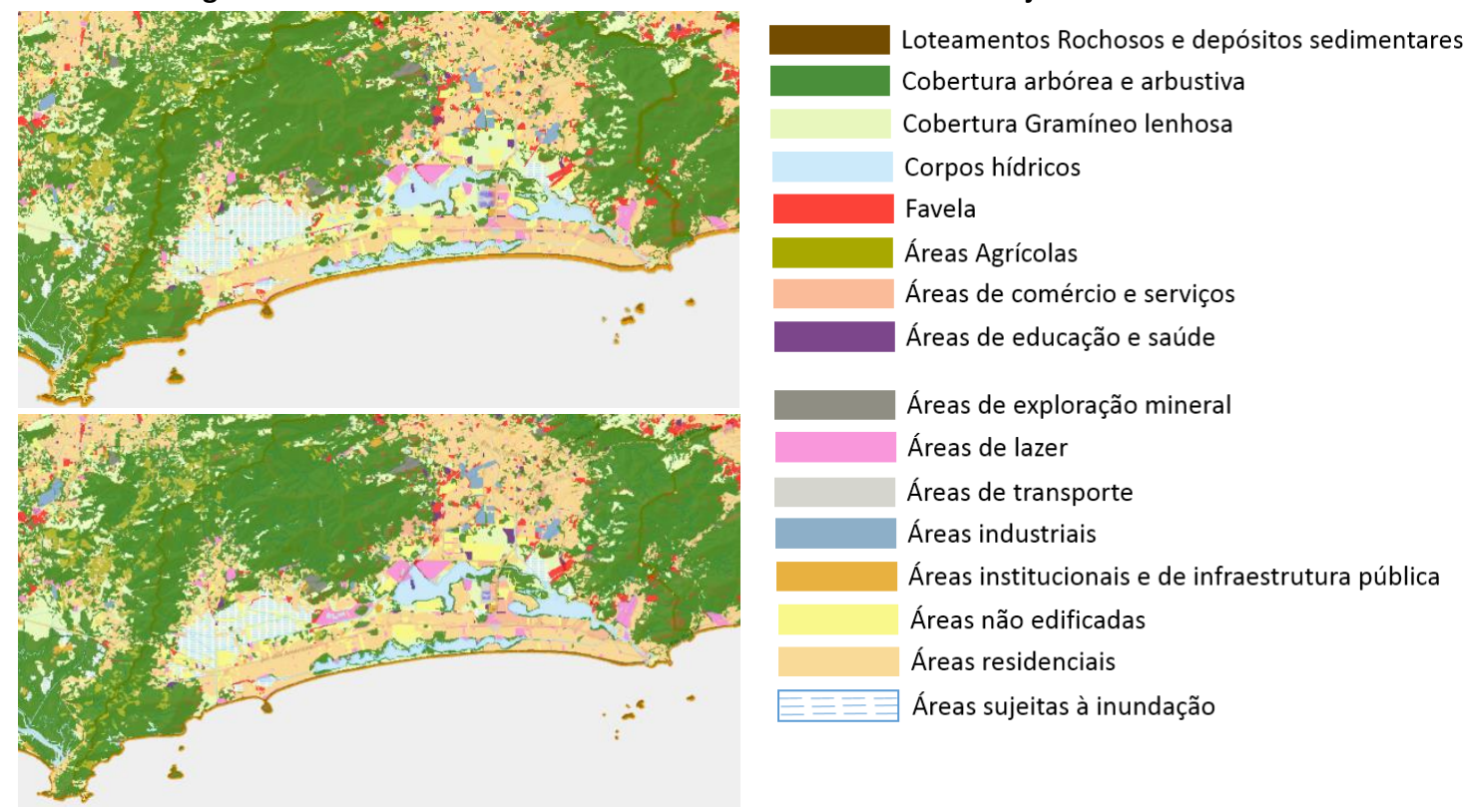

Fonte: IPP SIURB - Mapa Digital Uso do Solo (Mapas Digitais № 3221).

O número de imóveis comerciais e de serviço totalizaram 19.670 em 2011, número bem menor se comparado ao de imóveis residenciais (97.211). Porém, quando se analisa a metragem quadrada destes empreendimentos, eles ultrapassam a dos imóveis residenciais (Figura 10).

Figura 10: Número de imóveis por tipologias de uso x área construída total na RA Barra da Tijuca.

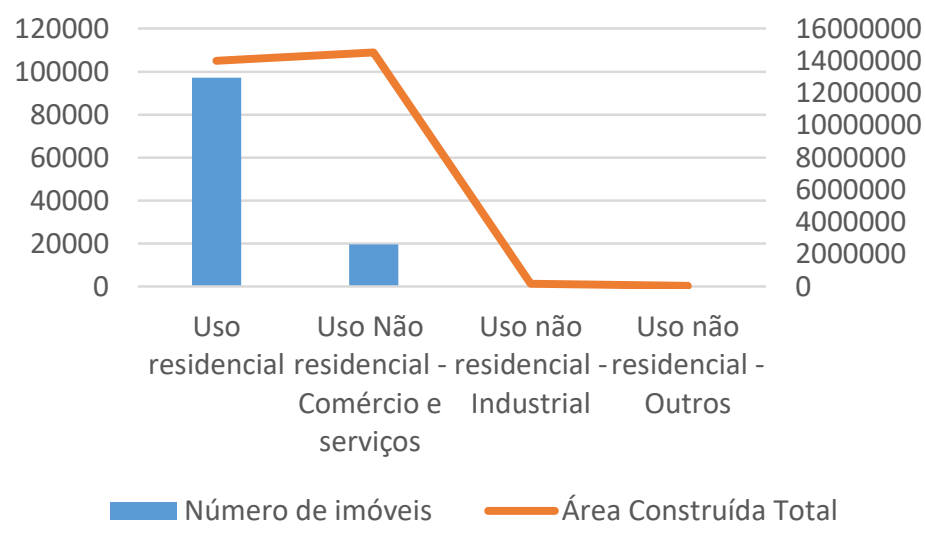

Fonte: Elaborado pela autora com dados do PortalGeo - Bairros Cariocas, 2011.

Um dos fatores que podem expressar estes dados é o número de shoppings centers na Barra da Tijuca. Em 2012 o bairro contabilizava quatro grandes empreendimentos (que se expandem com o passar do tempo) e com previsão de mais três shoppings. No total, as empresas investiram R\$ 


\section{Revista Nacional de}

Gerenciamento de Cidades

1,36 bilhão em centros comerciais na região e criaram mais $152 \mathrm{mil} \mathrm{m2}$ de área bruta locável (MOURA, 2012). Segundo José Isaac Peres, presidente da Multiplan, em entrevista para o Valor Econômico (MOURA, 2012), a migração de sedes de grandes empresas do centro para a Barra, reflete em um novo perfil de morador para o bairro, que são os executivos em busca de mais conforto e qualidade de vida.

\section{A CRIAÇÃO DE NOVAS FRONTEIRAS PELO SETOR IMOBILIÁRIO: O ESPRAIAMENTO DA MARCA "BARRA" NO BAIRRO DE JACAREPAGUÁ}

Segundo Associação de Dirigentes de Empresas do Mercado Imobiliário (ADEMI) (2011), 68,5\% de todas unidades habitacionais lançadas na cidade entre 2005 e 2010 estavam concentradas em quatro bairros da região Oeste: Barra da Tijuca, Jacarepaguá, Recreio e Campo Grande. Segundo relatórios da ADEMI de 2003 a 2013, os bairros da Barra da Tijuca e Recreio, que possuem a mesma região administrativa (R.A. XXIV); e Jacarepaguá (R.A. XVI) possuem os números mais altos em relação às unidades vendidas no primeiro semestre de 2004 a 2013 (Figura 11).

Figura 11: Número de Unidades Vendidas por bairro 2004 a 2013 (1 semestre)

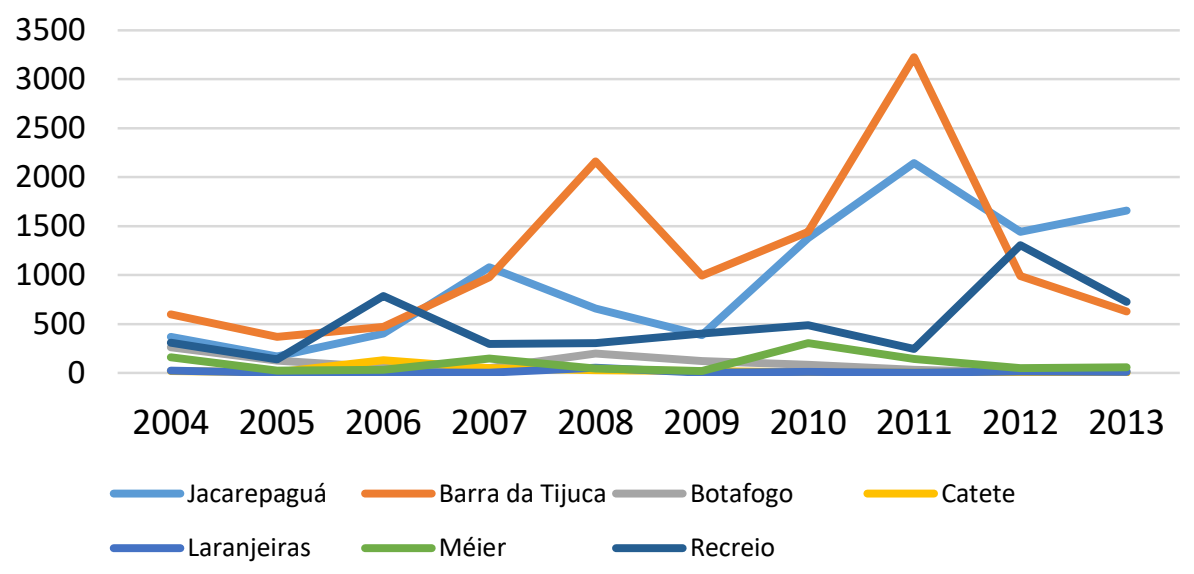

Fonte: Elaborada pela autora com dados dos relatórios semestrais da ADEMI de 2004 a 2013.

Porém, é possível verificar uma disputa entre os bairros da Barra da Tijuca e Jacarepaguá. "A história do processo de estruturação do espaço urbano na Barra da Tijuca e Baixada de Jacarepaguá está diretamente relacionada a produção capitalista imobiliária" (COCCARO, 2013, p. 03). Geralmente um dos dois bairros aparece como o primeiro lugar no ranking de unidades vendidas (Quadro 1). Segundo Rezende e Leitão (2003, online), "a urbanização da Barra da Tijuca e da Baixada de Jacarepaguá representa a etapa mais recente da produção de espaços residenciais seletivos na cidade do Rio de Janeiro". 


\section{Revista Nacional de}

Gerenciamento de Cidades

Quadro 1: Barra da Tijuca e Jacarepaguá como as grandes localizações de unidades vendidas.

\begin{tabular}{|c|c|c|}
\hline \multicolumn{3}{|c|}{ Primeiro lugar no ranking ADEMI de unidades vendidas } \\
\hline Ano & $\mathbf{1}^{\circ}$ semestre & $\mathbf{2}^{\circ}$ semestre \\
\hline 2003 & - & Jacarepaguá \\
\hline 2004 & Barra da Tijuca & Barra da Tijuca \\
\hline 2005 & Barra da Tijuca & Centro \\
\hline 2006 & Recreio & Barra da Tijuca \\
\hline 2007 & Jacarepaguá & Barra da Tijuca \\
\hline 2008 & Barra da Tijuca & Barra da Tijuca \\
\hline 2009 & Barra da Tijuca & Barra da Tijuca \\
\hline 2010 & Barra da Tijuca & - \\
\hline 2011 & Barra da Tijuca & Barra da Tijuca \\
\hline 2012 & Jacarepaguá & Jacarepaguá \\
\hline 2013 & Jacarepaguá & Cachambi \\
\hline
\end{tabular}

Fonte: Elaborado pela autora com dados dos relatórios ADEMI, 2003 a 2013.

Mas se a análise recair não somente nos dados da tabela e sim na malha urbana destes bairros, é possível verificar que a disputa se transforma em espraiamento. Espraiamento dos condomínios e da "marca" Barra no bairro de Jacarepaguá (Figura 12).

Figura 12 - Outdoor anuncia o futuro Shopping Metropolitano

Barra, empreendimento que, pelos limites atuais de bairros, fica em Jacarepaguá

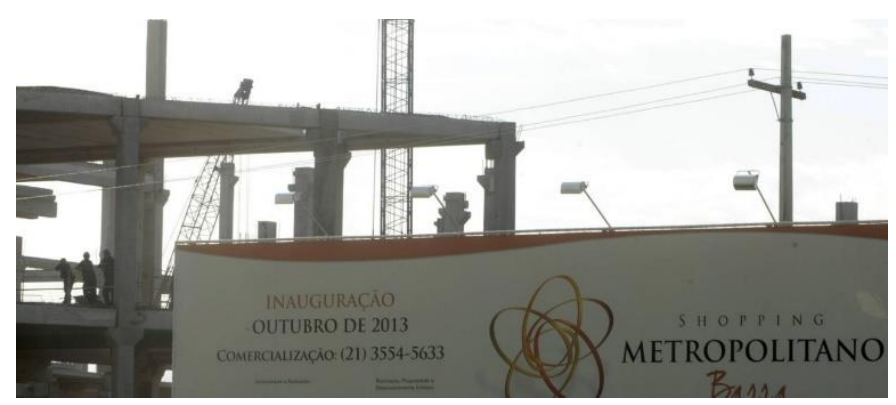

Fonte: Gustavo Stephan / O Globo, 2012.

Âncoras de atração, como o shopping Metropolitano Barra, a Casa de Espetáculos Barra Music e o Condomínio Caminhos da Barra, que utilizam o nome do bairro, situam-se em Jacarepaguá. Até mesmo o Riocentro, que sediou as discussões da Conferência Rio+20, embora esteja em Jacarepaguá, divulga seu endereço como sendo Barra da Tijuca.

$O$ bairro é mais valorizado quanto mais consolidado, mais estruturado for. $E$, quando comparamos a Barra com Jacarepaguá e Recreio, por exemplo, ela ainda é a região mais desenvolvida, com mais ruas asfaltadas e serviços. Houve uma tendência, principalmente com a 


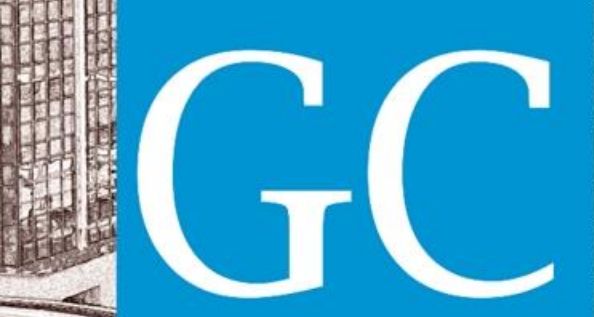

\section{Revista Nacional de}

Gerenciamento de Cidades

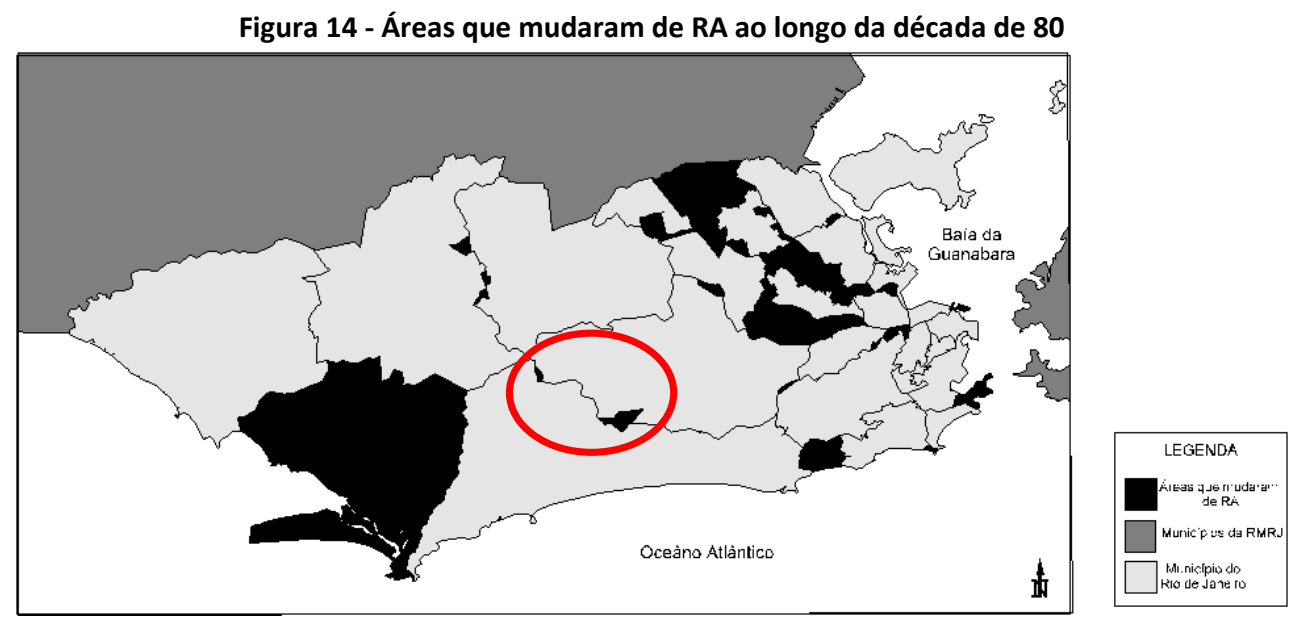

Fonte: NAJAR et. al. Utilização de um SIG para estudo da alteração dos limites político-administrativos do município do rio de janeiro, Ao longo da década de 80. 1a Semana Estadual de Geoprocessamento - RJ. "Geoprocessamento: Mitos \& Realidade", Rio de Janeiro, 1996.

Segundo Coccaro (2013) era necessária a redefinição dos limites entre estes dois bairros, principalmente no entorno do parque Olímpico. Em 2010 houve a tramitação do projeto de lei intitulado bairro Barra Olímpica (Lei número 807/2010). A justificativa do Vereador Carlos Caiado para redefinição dos limites e criação de um novo bairro recai na argumentação do marketing urbano, de promover a cidade de uma maneira a atrair pessoas e investidores e competir mundialmente.

\begin{abstract}
A realização na Cidade do Rio de Janeiro de um evento da magnitude dos Jogos Olímpicos, em 2016, representará, não temos dúvida, um marco para toda a Cidade e nosso povo. Afinal, como se costuma dizer, os olhos do mundo estarão voltados para nossa terra, pois serão mostradas, a par dos eventos esportivos propriamente ditos, as incomparáveis belezas da Cidade. Esta, portanto, é uma oportunidade ímpar, que merece, e precisará, ser lembrada para sempre, de todas as maneiras possíveis. Daí a motivação para a presente iniciativa, que pretende registrar indelevelmente os Jogos Olímpicos da Cidade do Rio de Janeiro, que certamente se constituirão em um dos mais memoráveis Jogos Olímpicos de toda a história desse grandioso evento mundial (RIO DE JANEIRO, 2010, online).
\end{abstract}

Este novo bairro surgiria a partir da subdivisão da Barra da Tijuca, Jacarepaguá e Camorim (Figura 15). A delimitação não é clara, porém, no artigo 3 relata-se que a partir da regulamentação da lei, será detalhado o perímetro, no entanto, será obrigatório que sejam incluídos o Riocentro, a área da futura Vila Olímpica, a área do antigo Autódromo e a área que abrigará o futuro Centro Metropolitano. Essas áreas até pouco tempo desprezadas pela construção civil, tornou-se, segundo Ferreira (2011, p.103) “o novo eldorado das empreiteiras cariocas" e, desta forma, incluídas de forma sistemática, no projeto de lei. O projeto continua a tramitar na Legislatura 2013/2016. 


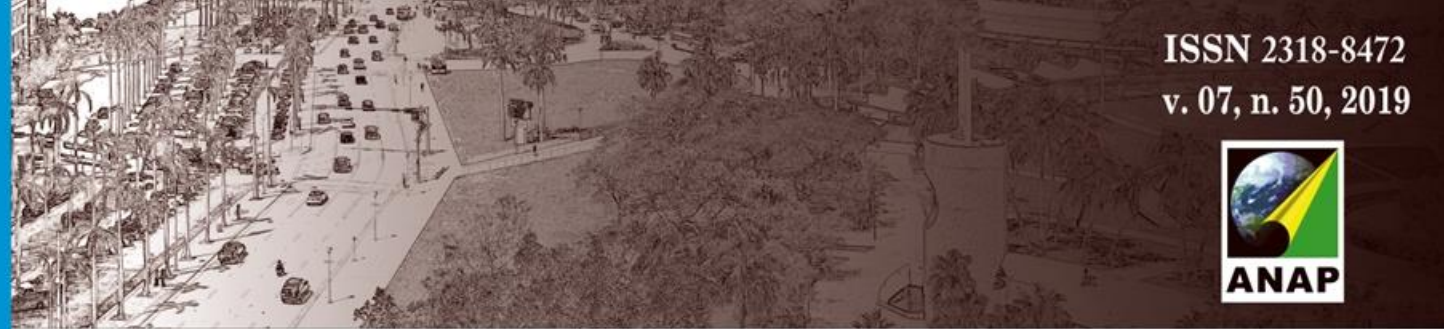

Revista Nacional de

Gerenciamento de Cidades

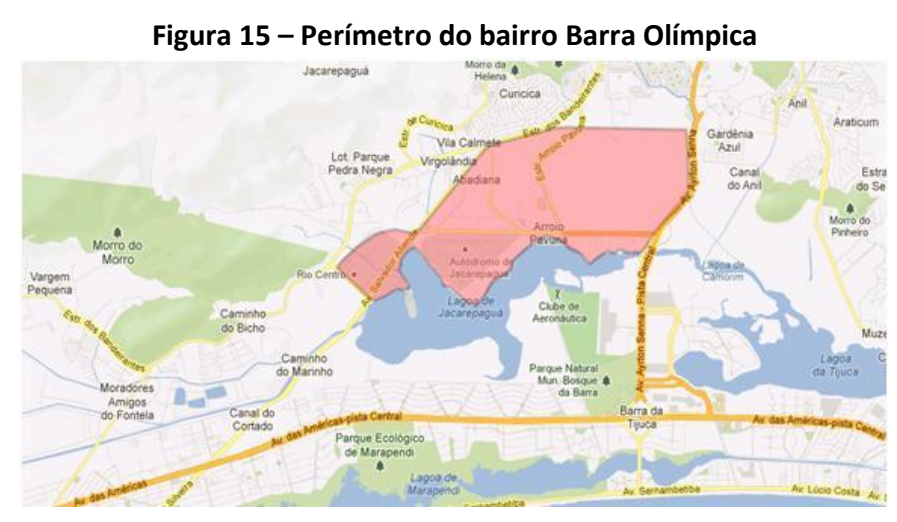

Fonte: Elaborada por COCCARO, 2013 com dados do PL 807/2010.

\section{CONSIDERAÇÕES FINAIS}

A Barra da Tijuca foi uma criação modernista que mostra características diferentes do restante da cidade. Ela é isolada fisicamente pelo parque Nacional da Tijuca e pela Pedra da Gávea, mas também socialmente, pois existe uma xenofobia do lado Leste da cidade para com o bairro e um ostracismo da Barra para com o restante. Esta questão de isolamento fez com que esta apresentasse um modo próprio de morar, mais próximo do estilo americano e mais afastado do modelo carioca.

A partir dos dados analisados, é possível caracterizar a Barra da Tijuca como um bairro de forte verticalização marcada pelo alto crescimento imobiliário. Também foi possível perceber que possui grandes vazios urbanos e áreas livres ou protegidas ambientalmente. Essas áreas vazias e de futuro capital imobiliário, se seguirmos a lógica demonstrada nos gráficos apresentados, reflete em grande parte o desenvolvimento da malha urbana ao longo dos anos que passou o bairro, onde a prática de estoque de reserva e os diversos boom's imobiliários foram partes presentes do contexto histórico da região. Segundo Coccaro (2013, p. 01) este crescimento se deu, pois, as terras, antes em condição de estoque de reserva do capital nas mãos de poucos donos, integram hoje uma "inovadora dinâmica, personificada em um urbano pronto para ocupar seu estratégico posicionamento de cidade global".

Esta área também foi escolha governamental de grandes infraestruturas viárias, como as avenidas de interligação com o restante da cidade e a implantação dos BRT's. Também é local da inserção de grandes eventos internacionais, como o Pan-Americano e as Olimpíadas.

O poder aquisitivo da população é alto e os equipamentos de comércio e serviço estão voltados para satisfazer a necessidade desta classe. O consumo e o lazer se fundiram e os shopping são os grandes templos desse bairro. Desta forma, segundo Szmerecsanyi (1999, p. 24) o lazer tornou-se manipulador, pois é comercial e político, transformando-se em "fuga da realidade, 

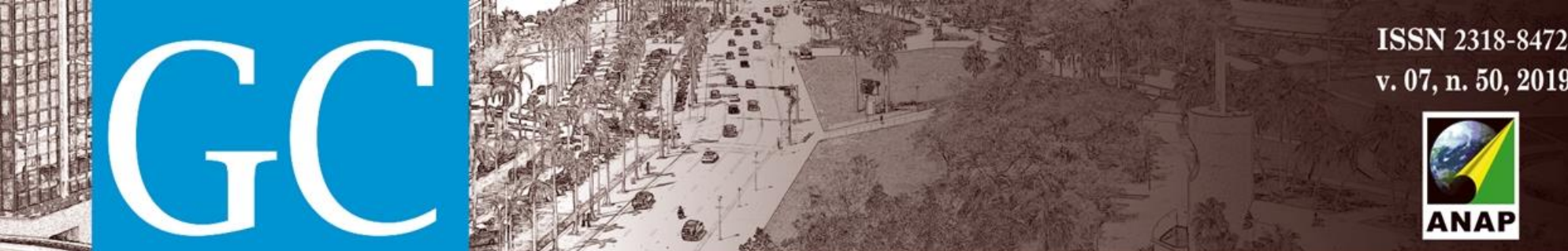

Revista Nacional de

Gerenciamento de Cidades

SCHMIDT, Selma. Bairros periféricos da Barra da Tijuca foram os que mais cresceram entre 2000 e 2010. Entre favelas, foi a Mangueira. Jornal O Globo, 01 jul. 2011.

SECRETARIA MUNICIPAL DE MEIO AMBIENTE - SMAC Território e Meio Ambiente, 2005. In PortalGeo - Bairros Cariocas. Disponível em< http://portalgeo.rio.rj.gov.br/bairroscariocas/index_bairro.htm> Acesso em: 12 de fev. 2015.

SILVEIRA, Aline F.; BUENO, Laura M. M. Sustentabilidade e Vivências em uma Bacia Hidrográfica Urbana: resultados de intervenções recentes, Campinas/SP, Brasil. Encuentro de Geógrafos de América Latina, Perú, p. 1-18, 2013.

SZMERECSANYI, Maria Irene. UMA PÓS MODERNIDADE SECULAR? Designio - Revista de História da Arquitetura e do Urbanismo, São Paulo, 2014. p.23-32 